\title{
Paediatric gastrointestinal volvulus: Twisting our heads around unusual diagnoses
}

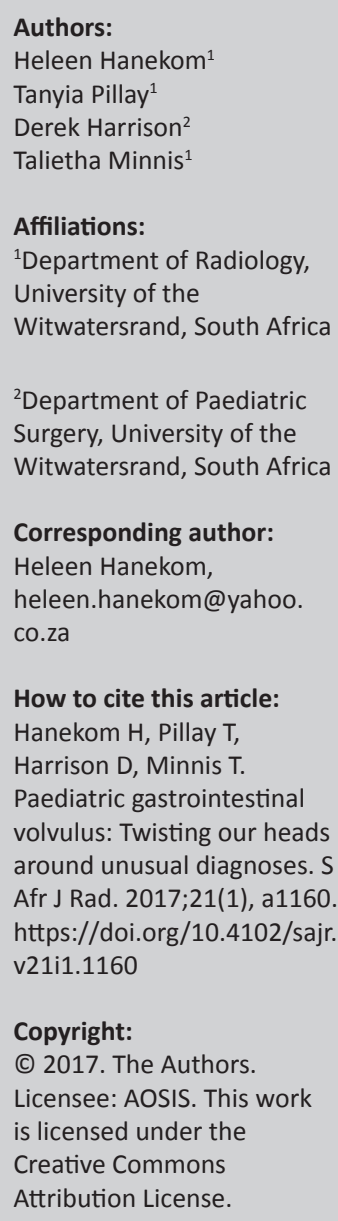

\section{Copyright:}

C 2017. The Authors. Licensee: AOSIS. This work

is licensed under the

Creative Commons

Attribution License.

Introduction: Volvulus of the gastrointestinal tract is a rare entity. Clinical symptoms are often non-specific, and imaging plays a vital role in the identification and diagnosis.

Aim: An educational poster highlighting the specific radiological features of gastric, midgut, caecal and sigmoid volvulus.

Conclusion: Recognition of the radiological appearance of volvulus of the gastrointestinal tract is essential to make a prompt diagnosis and thus avoid life-threatening complications.

Note: A selection of conference abstracts: RSSA/SASPI Paediatric Imaging Congress, 03-06 November 2016, Spier Estate, Stellenbosch, South Africa. Faculty collaborators: Professor Kassa Darge (Body Imaging, University of Pennsylvania, Philadelphia, USA), Professor Edward Lee (Thoracic Imaging, Harvard University, USA), Professor Beverley Newman (Cardiac Imaging, Stanford University, California, USA), Professor Kimberly Applegate (Image Gently and Body Imaging, Emory University, Atlanta, USA) and Professor Savvas Andronikou (Thoracic Imaging, University of Bristol, UK) supported by South African Paediatric Radiologists, co-ordinated by Dr Jaishree Naidoo, President of the African Society of Paediatric Imaging and Head of Division of Paediatric Radiology, Charlotte Maxeke Johannesburg Academic Hospital. 